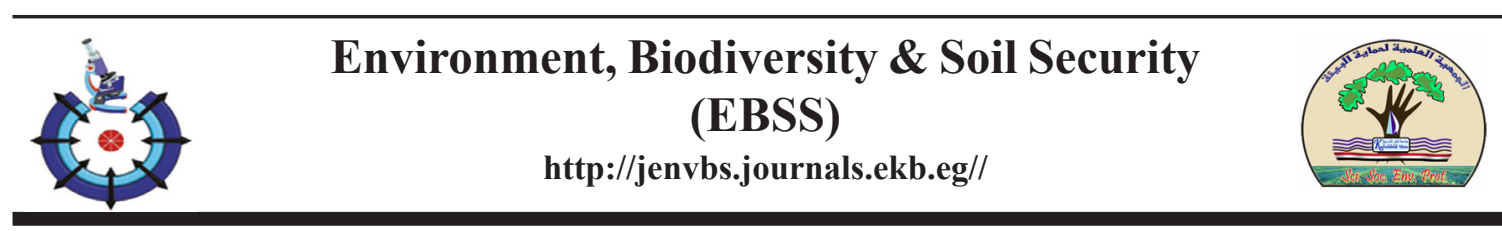

\title{
Comparative Study on Rice Germination and Seedling Growth under Salinity and Drought Stresses
}

\author{
M. E. Negm, W.H. El-Kallawy* and A. G. Hefeina
}

Rice Research \& Training Center, 33717, Sakha, Kafrelsheikh, Filed Crops Research Institute, Agricultural Research Center, Egypt.

\begin{abstract}
$\mathbf{R}^{1}$ ICE is very important crop in Egypt and the production of rice yield faced many challenges such as, saline soil and drought. For salinity about $30 \%$ of lands affected by salinity specially northern part of delta, besides, in Egypt the people increase continuously but the water sources are constant so year by year the problem increase. The rice cultivars differed in salinity and drought tolerance in the various stages of plant life, so, study of rice tolerance in germination and seedling stage play a vital role to rice breeder to select good rice donors to improve tolerance to salinity and drought. This investigation was carried out in the lab of Rice Research and Training Center (RRTC), Sakha station, Kafrelsheikh, Filed Crops Research Institute Egypt, during 2017 and 2018 seasons, to study the inheritance of some germination and early seedling traits associated with salinity and drought tolerance. Eight rice genotypes namely; Sakha102, Sakha104, Sakha105, Sakha106, Giza178, A22, IRAT170, and WAB56125 were evaluated under salt solutions $(\mathrm{NaCl})$ of distilled water as a control, 3.5 or $7 \mathrm{dSm}^{-1}$ salt concentrations according to the treatments and drought stress caused by two concentration of sorbitol (10 and $20 \mathrm{ml} / \mathrm{l})$. Significant genetic variation was found among rice cultivars for seedling vigor under salt and drought stress conditions. Thus, could use the tolerance verities in breeding program to improved tolerance to salinity and drought. The phenotypic coefficient variability ( $\mathrm{PCV} \%$ ) was higher than genotypic coefficient variability ( $\mathrm{GCV} \%$ ) for all traits, indicating the existence of wide genetic variability among these genotypes. This study indicated that the rice variety A22 followed by WAB56-125 were the most tolerant to salt and drought stress conditions. Meanwhile, Sakha104 could use a good donor underwater deficit in breeding programs.
\end{abstract}

Keywords: Germination, Heritability, Genetic advance, Oriza sativa, Osmotic stress, Rice, Seedling vigor.

\section{Introduction}

Rice (Oryza sativa L.) is the most important crop after wheat. It is a staple food for nearly one half of the world population since most of them live in developing countries. Moreover, it is a very important cereal crop in Egypt for consumption and exportation, in which an important source for hard currency. The total rice cultivated area is about 1.54 million fed which produces about 6.08 million tons of paddy rice (RRTC, 2014). Rice is mainly cultivated in the northern Nile-Delta of Egypt, where, salt affected soils are prevailing.
Furthermore, poor quality water is used as irrigation water in the target domain area (30$35 \%$ of rice cultivated area) of salt affected soils. The area of saline soil is expected to increase in Egypt as a result of fresh water shortage and climate change. Rice under saline soil needs especial management rather than normal soil. (Zayed et al. 2014). Several biotic and a biotic stress decrease yield of rice, a biotic stress such as drought, salinity, high and low temperature and flooding (Farid et al. 2016). Rice crop considered one of the major water consuming crops where

*Corresponding author e-mail: elkallawywael@yahoo.com

Received 14/4/2019; Accepted 8/8/2019

DOI: 10.21608/JENVBS.2019.11933.1058

C2019 National Information and Documentation Center (NIDOC) 
continuous submerging is the only irrigated method used. Thus, drought is the most serious stress less rice production nowadays. Where about one third of rice cultivated area suffer from water shortage (Abd Allah et al. 2016). Generally, the effect of $\mathrm{NaCl}$ was significantly stronger than that of sorbitol in cv. Bomba, whereas in cv. Bahia the effects of both stress agents were comparable (Wankhade et al. 2010). Increasing salinity concentration of $\mathrm{NaCl}$ gradually reduced averages of germination and seedling traits (Kandil et al. 2012). The current work aimed to evaluation some rice genotypes for germination and seedling characters at early growth under salinity and drought stress to be used as good donors in improving rice tolerance to such stresses.

\section{Material and Methods}

The experiments were conducted in the Lab of Rice Research Department during 2017 and 2018 seasons. Eight rice genotypes namely; Sakha102, Sakha104, Sakha105, Sakha106, Giza178, A22, IRAT170, and WAB56-125 were chosen based on previous studies according to (RRTC, 2014). These genotypes have a wide range of variation due to their different genetic background in salt and drought tolerance as presented in Table 1.

Thirty seeds for each genotype in each treatment were germinated on a filter paper in $9 \mathrm{~cm}$ diameter Petri dishes. The salt treatments included distilled water as a control, 3.5 and $7.0 \mathrm{dSm}^{-1}$ salt concentrations by solving $\mathrm{NaCl}$ in distilled water to make two salinity stresses, the critical limit of salinity in rice is $3 \mathrm{dSm}^{-1}$ so, using 3.5 and 7.0 in this study to estimate the differences between varieties to tolerance in rice. Drought stresses involved two concentrations of sorbitol (10 and $20 \mathrm{ml} / \mathrm{L}$ ) by adding sorbitol to distilled water to make artificial drought. Sodium chloride was used to prepare the salt solution because of safety without causing any precipitation of different ions. Ten $\mathrm{ml}$ of appropriate solution was applied to each Petri dish. The Petri plates were arranged in three replicates for each treatment in factorial experiment design. Germination room temperature was maintained at $25 \pm 1^{\circ} \mathrm{C}$. Petri plates were periodically checked and water was applied to compensate evaporation. The number of seeds that sprouted and germinated was counted daily up to 15 days. Shoot and root length, fresh weight and seedling fresh weight of ten seedlings randomly selected from each repetition were measured until 15 days after treatment application by using a scale. Germination energy percentage (GE \%) were measuring after $4^{\text {th }}$ as number of germinated seeds divided into total seeds and at final count, final germination percent (FGP) were calculated after $15^{\text {th }}$ as number of germinated seeds divided into total seeds, according to Anbumalarmathi and Mehta (2013). The experimental design was a split plot with three replications and calculating the genetic parameters, according to formula suggested by Burton (1952) and Heritability in broad sense $(\mathrm{Hb})$ estimated according Hanson et al. (1956). While Genetic advance estimated according Johnson et al. (1955). Data were subjected to statistical analysis; employing F-test for significance at $\mathrm{P} \leq 0.05$ and LSD values were computed in different statistical groups according to the described method by Little and Hills (1978).

\section{Results and Discussion}

Phenotypic and genotypic coefficient of variability are presented in Table 2 . The rice genotypes showed a wide range of variation for all studied traits, where the genotype mean squares were highly significant for all studied traits in two seasons. Thus, the selection for improved traits among these genotypes would be effective in all traits. The differences among rice genotypes in germination traits might be due to the genetic background and heredity variation, where, some varieties have a genes tolerance of salinity and drought and other varieties sensitive to adverse conditions. Phenotypic coefficient of variability (PCV\%) was higher than genotypic coefficient variability $(\mathrm{GCV} \%)$ for all traits

TABLE 1. Origin, parentage, type of the eight rice genotypes.

\begin{tabular}{clll}
\hline Variety & \multicolumn{1}{c}{ Origin } & \multicolumn{1}{c}{ Parentage } & Type \\
\hline Sakha102 & Egypt & Giza176/Milyang79 & Japonica \\
Sakha104 & Egypt & GZ4096-7-1/GZ4120-2-5-2 \\
Sakha105 & Egypt & GZ5581-46-3/GZ4316-7-1-1 & Japonica \\
Sakha106 & Egypt & Giza177/Hexi30 & Japonica \\
Giza178 & Egypt & Giza175/Milyang49 & Indica/ Jponica \\
A22 & Sri-lank & IR47664 & Indica \\
IRAT170 & Côte d'Ivoire & IRAT13/Palawan & Tropical/Japonica \\
WAB56-125 & Côte d'Ivoire & IDSA6/IAC164 & Indica \\
\hline
\end{tabular}

Env. Biodiv. Soil Security Vol. 3 (2019) 
indicating the existence of wide genetic variability in these genotypes and that selection to improve such traits could be practiced effectively in the segregating populations after crossing among them. The genetic coefficient of variability (GCV) for all studied traits ranged between $(9.17 \%)$ for seedling fresh weight to $(37.33 \%)$ for root length in 2016, furthermore, The genetic coefficient of variability $(\mathrm{GCV})$ ranged between $(10.02 \%)$ for root fresh weight to $(36.13 \%)$ for root length in 2018 , indicating that these traits might be more genotypically controlled and it would be possible to achieve further improvement for them. Anbumalarmathi and Mehta (2013) reported that seedling length of all the rice varieties decreased with an increase in salinity. Reduction of seedling height is a common phenomenon of many crop plants grown under saline conditions.

The genetic coefficient of variability refers to the importance role of the additive and non-additive genetic variance in the inheritance of these traits. Moreover, seed germination was quantitative trait controlled by several gens and strongly affected by salt and drought stress. These differences between rice varieties dependent on genetic variance can use in hybridization to improve tolerance to salinity and drought. Estimates of heritability in broad sense varied from 75.80 to $99.48 \%$ in 2017 and from86.89 to 98.38 in 2018 seasons which were high in general for all the studied traits. Furthermore, the genetic advance results indicating that achieving the gain in selection each generation from these genotypes in breeding program. High heritability accompanied with high genetic advance indicating lesser environmental influence and were under the control of additive gene effect Sathya and Jebaraj (2013).

The germination and seedling traits under stresses

Data in Table 3 showed that germination energy percentage (GE \%) of the studied rice on $4^{\text {th }}$ day was significantly low at the highest concentration of both sorbitol and $\mathrm{NaCl}$. With increasing doses of stresses (sorbitol and $\mathrm{NaCl}$ ), GE\% gradually decreased comparing with the control. Although, both sorbitol and $\mathrm{NaCl}$ inhibited seed germination where, sorbitol showed inhibitory effects than that of $\mathrm{NaCl}$. Sakha106, A22 and Sakha104 rice genotypes showed high germination $\%$ under high osmotic stress conditions. Furthermore, final Germination percent (FGP\%) of the studied rice at day $15^{\text {th }}$ was significantly low at the highest concentrations of sorbitol and $\mathrm{NaCl}$. Although, both sorbitol and $\mathrm{NaCl}$ inhibit seed germination, $\mathrm{NaCl}$ showed more inhibitory effects than that of sorbitol. Giza178, A22 and WAB56-125 rice genotypes showed the highest germination in most osmotic stress conditions for FGP \%. These results are in agreement with those reported by Wankhade et al. (2010) studied some developmental and anatomical features in control and $\mathrm{NaCl}$-stressed seedlings of two Japonica rice cultivars. Responses ascribed to osmotic stress were differentiated from those related to the ionic component of salinity by using in parallel a non-penetrating osmoticum (sorbitol). The main difference between them was the intensity of the response as a function of the stress agent. High levels of salinity affected germination traits might be due to toxic effects of salinity stress and high osmotic pressure preventing water absorption Kandil et al. (2012). Salinity decreased germination of seeds which are directly related to the amount of absorbed water by the seed Ologundudu et al. (2014). The phenotypic variance for shoot and root length induced osmotic stresses by sorbitol and $\mathrm{NaCl}$ treatments were varied greatly. Shoot length in control was maximum $(15.67$ and $16.33 \mathrm{~cm})$ in Sakha104 at both seasons of study, respectively.

Overall shoot growth in the two different doses of sorbitol were more than the values found in the two different $\mathrm{NaCl}$ concentrations in two seasons. Shoot length in all concentrations of sorbitol and $\mathrm{NaCl}$ were lower than the control one. Furthermore, root length was the lowest in IRAT170 rice genotype and the highest in Sakha104, Sakha106 and A22 rice genotypes under the two salinity levels compared to control, but, the concentration of sorbitol increased the root length. On the other hand, the doses of $\mathrm{NaCl}$ stresses inhibited the root growth. The present investigation indicated that, the presence of variability among the tested genotypes with respect to all the traits studied. Sarkar et al. (2012) tested varieties at different levels of salinity and reported that this technique is capable of distinguishing among rice varieties for salinity tolerance at the seedling stage. 


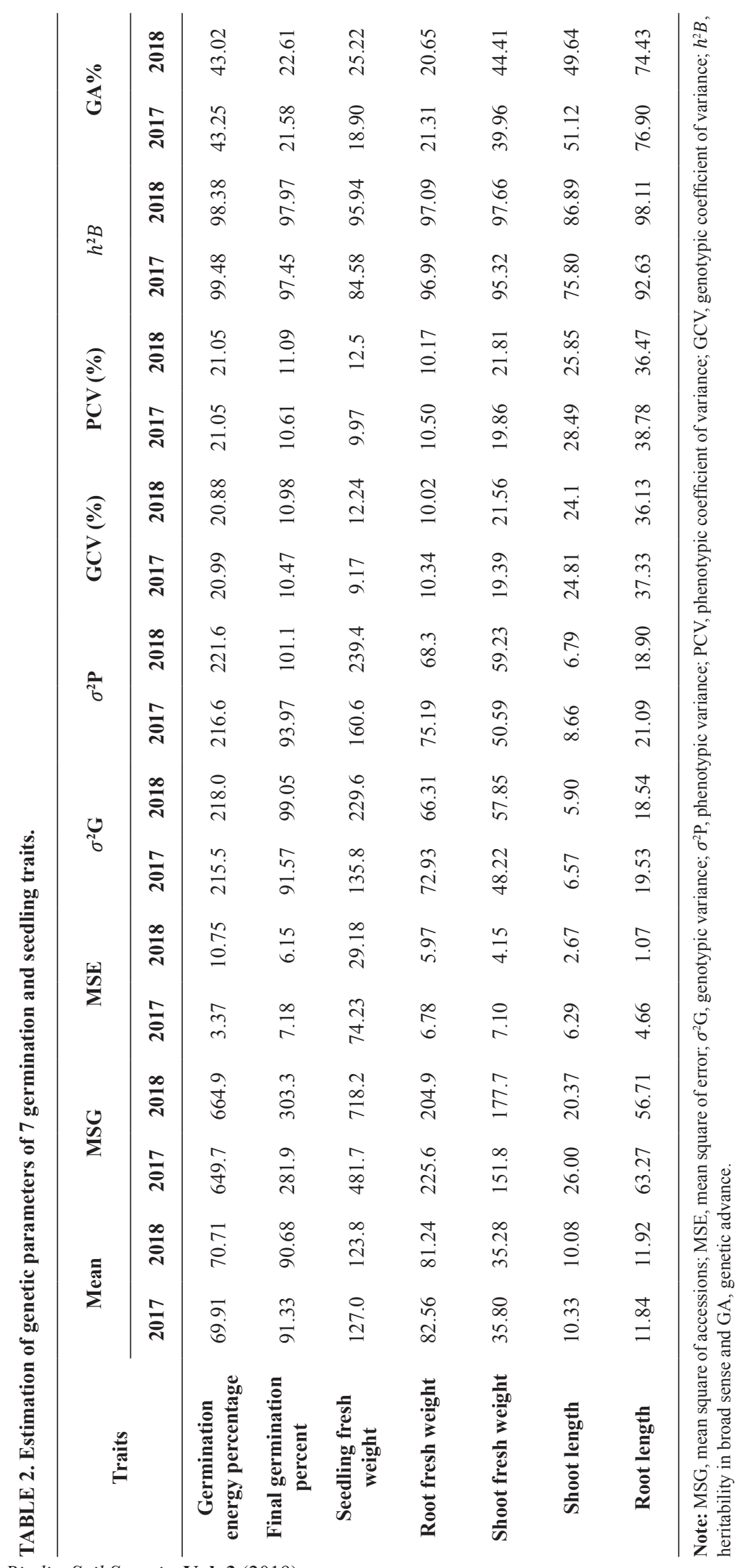



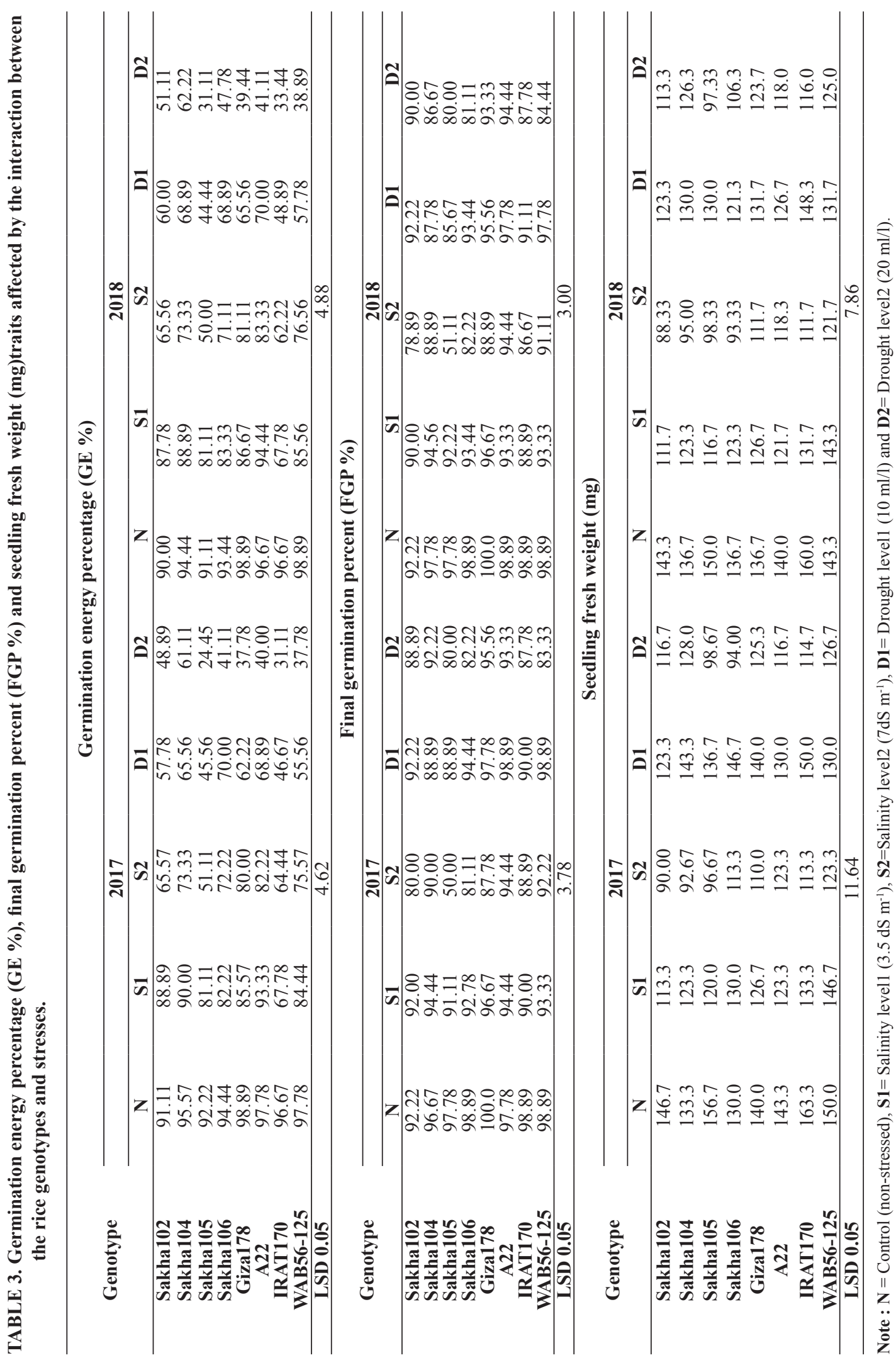

Env. Biodiv. Soil Security Vol. 3 (2019) 
Concerning seedling fresh weight, data in Table 4 indicated that, among eight varieties rice genotype WAB56-125 scored the highest mean value under salinity conditions in the two seasons of study. Furthermore, IRAT170 and Sakha104 rice genotypes exhibited the highest mean values under artificial drought conditions of drought level 1 and level 2 in both seasons, respectively. On the other side, the lowest mean values were obtained by Sakha102 rice genotype under salinity conditions. These results are in agreement with the results obtained by Kandil et al. (2012) studied response of some rice (Oryza sativa L.) cultivars to germination parameters under salinity stress, where, the results showed that rice cultivars significantly varied in means of final germination percentage (FGP), root length, shoot length, root fresh weight, shoot fresh weight and seedling height reduction.

The root fresh weight was decreased with increasing salinity levels. At high level of salinity, fresh weight reduction in all the variety was serious. The genotype WAB56-125 was the best variety under salinity stress. Meanwhile, Sakha104 were the best varieties under drought stress for this trait in two seasons. The differences among rice cultivars in germination traits might be due to the genetic factors and heredity variation among the eight rice cultivars under study which caused differed in germination traits Farid et al. (2016).

Shoot fresh weight was inversely proportional to salt concentration levels; it decreased with increase in salt concentration levels. This trait was relatively less sensitive to salt than root fresh weight, especially at higher salt concentrations. Cultivars also differed and showed variability in the response of shoot fresh weight to salt concentration. In this study, under all salinity levels, shoot fresh weight of all varieties was significantly affected, while Sakha102 showed the highest salt sensitivity in all salinity treatments in two seasons. Furthermore, IRAT170 was the best genotype for shoot fresh weight under the two drought stresses in two seasons.

\section{Rice genotypes and difference stresses}

Table 5 showed that the most stresses effect on the genotype in the germination and seedling was high salinity level for most studied traits followed by the high drought level especially in germination energy percentage. Moreover, the best genotype was Sakha104 for Germination energy percentage $\%$ and the high drought level the most stresses effected on the Germination energy percentage \%. The results showed also Sakha104 the best one for shoot length with the high effect of high salinity level on this trait. Furthermore, Sakha104 and Sakha106 exhibited the good performance without any significant differences between them for root length and the high salinity level decrease the root length more than other stresses in two seasons. The high salinity level the most stresses decrease the final germination percentage, seedling fresh weight and shoot fresh weight. Moreover, the high salinity and drought level effects on root fresh weight without any significant differences in two seasons. Giza178 and A22 were the best genotypes for Final germination percentage $\%$, WAB56-125 and IRAT170 for Seedling fresh weight, Root fresh weight and shoot fresh weight in two seasons, these results indicating that could use these varieties in breeding program to improve these traits under salinity and drought conditions.

\section{Conclusion}

This study indicated that could use $\mathrm{NaCl}$ and Sorbitol to distinguish between rice varieties depending on salinity and drought tolerance. Based on studied traits on germination and seedlings it could be concluded that, under saline soil conditions the rice varieties A22 and WAB56-125 the most desirable parent and can be cultivated under these environments. Furthermore, Sakha104 followed by IRAT170 the most parents under drought stress and can use these two varieties to face water shortage. From genetic parameters the results showed that presence the genetic difference between eight varieties and could use the tolerance varieties in breeding program to improve salinity and drought tolerance. 


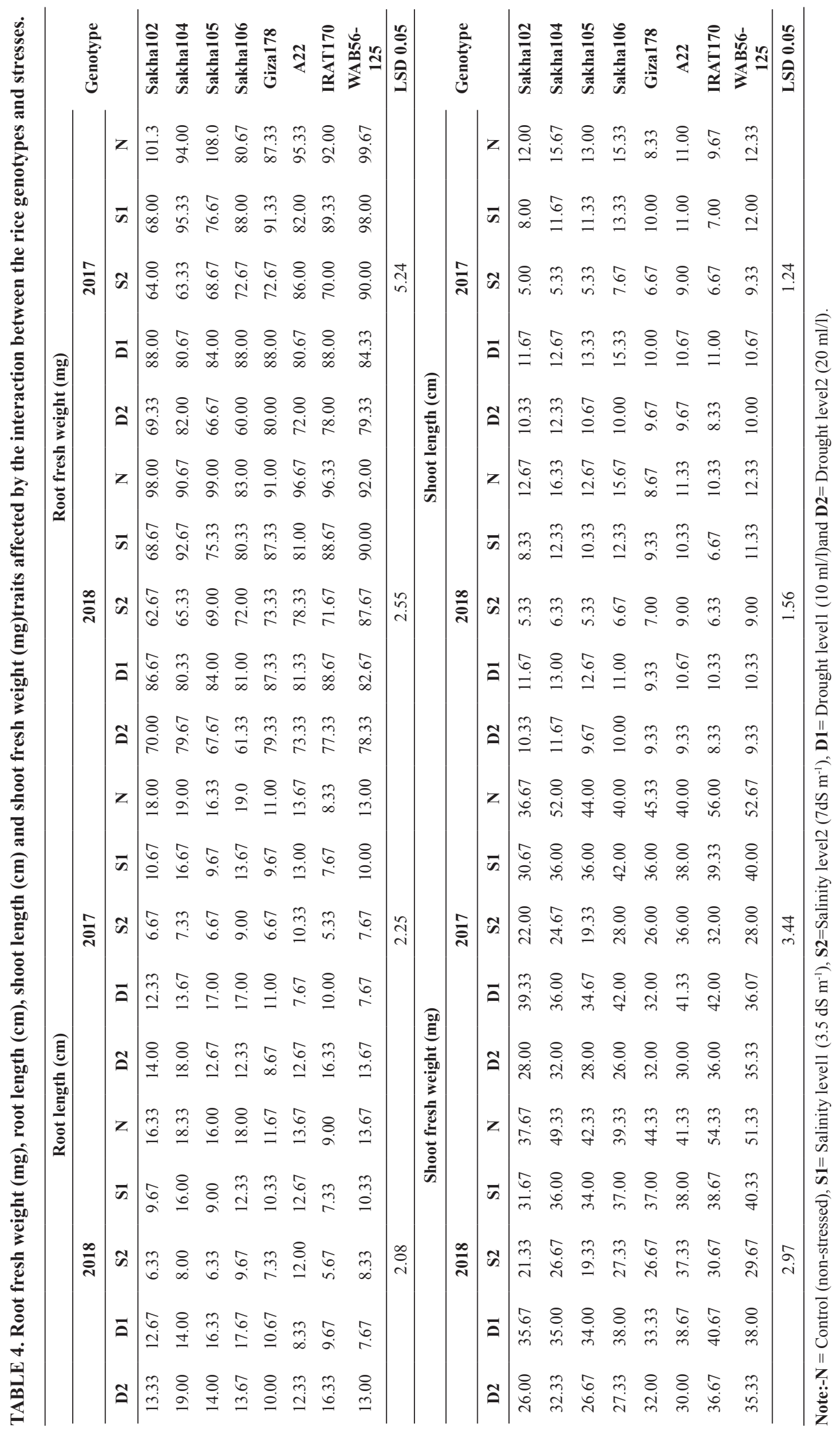

Env. Biodiv. Soil Security Vol. 3 (2019) 


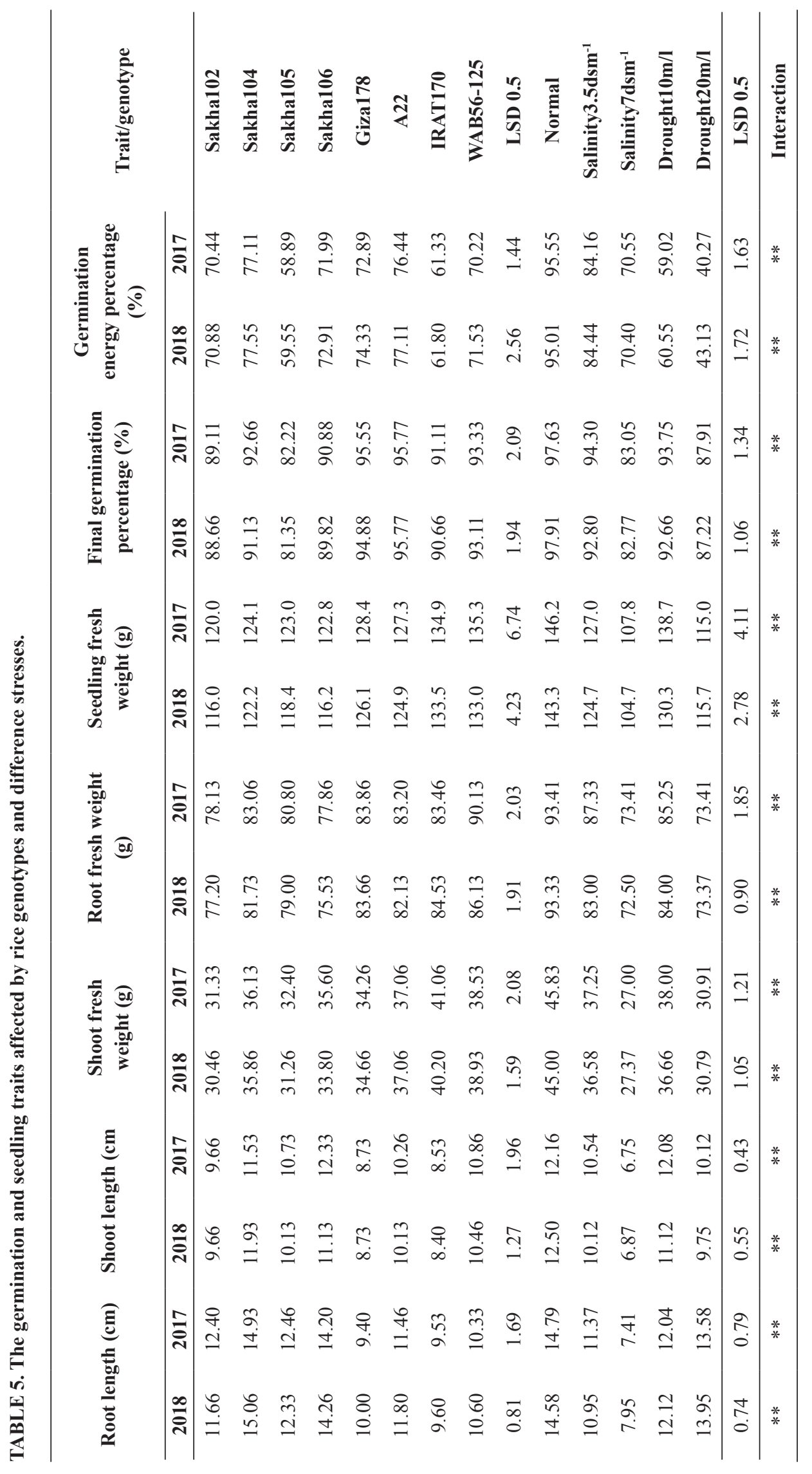

Env. Biodiv. Soil Security Vol. 3 (2019) 


\section{References}

Abd Allah, A.A.; Shimaa. A. Badawy and A.A. Eliba (2016) Response of some root and yield traits to water stress for some rice varieties. Journal of Agricultural Research 42 (3): 352-364.

Anbumalarmathi, J. and P. Mehta (2013) Effect of Salt Stress on Germination of indica Rice Varieties. $\operatorname{EJBS} 6$ (1): 1-6.

Burton, G.W. (1952) Quantitative inheritance in grasses.Proceeding of $6^{\text {th }}$ International Grassland Congress, Pennsylvania State College, 17-23 (1), 277-283.

Farid, M.A.; A.A. AbouShousha; M.E.A. Negm and S.M. Shehata (2016) Genetical and molecular studies on salinity and drought tolerance in rice (Oryza sativa L.)". Journal of Agricultural Research 42(2): 1-23.

Hanson, C.H.; H.P. Robinson and R.E. Comstock (1956) Biometrical studies on yield in segregating populations on Korean Lespedea. Agron. J., 48, 268-272.

Johnson, H.W.; H.F. Robinson and R.E. Comstock (1955)Estimates of genetic and environmental variability in soybean. Agron. $J ., 47(7): 314-318$.

Kandil, A.A.; A.E. Sharief and E.S.E. Nassar (2012) Response of some rice (Oryza sativa L.) cultivars to germination under salinity stress. International Journal of Agriculture Sciences, 4 (6): 272-277.
Little, T.M., and F.J. Hills (1978) Agricultural Experimentation - Design and Analysis. John Wiley \& Sons, Inc., New York, USA, p. 53-63.

Ologundudu, A.F.; A.A. Adelusi and R.O. Akinwale (2014) Effect of Salt Stress on Germination and Growth Parameters of Rice (Oryza sativa L.). Not Sci Biol, 6 (2): 237-243

RRTC (2014) Rice research and training center, Annual report agronomy.Sakha, Kafr El-Sheikh, Egypt.

Sarkar, N.C.; B. Mondal; D. Rajkumar and R.K. Maiti (2012) Salt tolerance of thirteen rice (Oryza sativa L.) varieties at germination and seedling stages. Research on Crops, 13 (3): 795-803.

Sathya, R. and S. Jebaraj (2013) Heritability and genetic advance estimates from three line rice hybrids under aerobic condition. International Journal of Agricultural Science and Research (IJASR), 3 (3):69-74.

Wankhade, S.D.; B. Abdellatif; M.A. Isabel and C. Maria-Jesus (2010) Phenotypic indicators of $\mathrm{NaCl}$ tolerance levels in rice seedlings: variations in development and leaf anatomy. Acta Physiologiae Plantarum. 32(6):1161-1169.

Zayed, B.A.; A. Salem and O.A.M. Ali (2014) Physiological characterization of Egyptian salt tolerant rice varieties under different salinity levels. Life Science Journal (11): 1264-1272. 